\title{
Analysis of the total phosphorus runoff in the Neva River
}

\author{
Vladislav Shelutko , Alla Govor, and Denis Alexeev \\ Russian State Hydrometeorological University, 79 Voronezhskaya st., 192007, St. Petersburg, Russia
}

\begin{abstract}
The paper deals with the problems of water quality assessment taking into account the features of hydrochemical information. The analysis of dynamics of total phosphorus into the Neva River runoff from 1978 to 2017 is presented.
\end{abstract}

\section{Introduction}

Distributions of long-term mean values of total phosphorus concentrations along the length of the Neva River, which calculated from observational data, are complex and not always physically justified [1]. An even more complex picture is presented by annual changes in concentrations. Because of this the possibility of using the available observational data on the Neva River is quite questionable in solving a variety of problems (the changes in the phosphorus content over time, the effect of the urban and adjacent territories on the phosphorus content in the river flow, etc.) In this regard, this work aims to study the variation of total phosphorus along the Neva river, analyze the contradictions in the database that already exists.

To reach this goal, the following tasks were set:

- Analysis of annual changes, variation of long-time mean values of total phosphorus concentrations in time.

- Analysis of variations of these characteristics along the Neva River.

- Exploration of possible contradictions in database and elaboration of for associated issues.

In carrying out the research the database of total phosphorus concentrations in the Neva River was used. Dataset was provided by the Northwest Department of Hydrometeorology and Environmental Monitoring. Observations were made during the period from 1978 to 2013.

The first step of the research involved mathematical characteristics being calculated for the entire original dataset, namely: $\mu$ - mean value, $\mathrm{s}-$ sample standard deviation, $\mathrm{Cv}-$ coefficient of variation, $g$ - coefficient of skewness.

\section{Materials and methods}

To solve the following issues statistical methods of processing data were used (eg: the

* Corresponding author: shelutko@rshu.ru 
method of regional generalization, hydrological analogy and integral curves of average annual total phosphorus concentrations in every stationary observation point on the Neva River )[2].

The next stage of the study consisted of the calculation of mathematical characteristics for the whole dataset of each stationary observation point.

Stationary observation points: Bol'shaya Neva, Branch Bol'shaya Nevka Branch Malaya Nevka, Branch Malaya Neva, were united in one stationary observation point named "Estuary" in order to define mathematical characteristics of average annual total phosphorus concentrations in estuary of the Neva River. The following process was implemented by means of the following formula:

$$
S_{i}=\sum_{j=1}^{4}\left(S_{\mathrm{ji}} * Q_{j i}\right) / \sum_{j=1}^{4} Q_{\mathrm{ji}}
$$

where $S_{i}$ - average annual total phosphorus concentrations in the Neva river in stationary observation point Estuary in ith year, Qji - average annual runoff volume in $\mathrm{j}$ th stationary observation point $(\mathrm{j}=1,2, \ldots 4)$ in ith year, Sji average annual total phosphorus concentrations in $\mathrm{j}$ th stationary observation point $(\mathrm{j}=1,2, \ldots 4)$ in $\mathrm{ith}$ year.

Qji for every stationary observation point was determined by reference of Nezhikhovskiy [3], as follows: in the estuary of Bol'shaya Neva $60 \%$ of $Q j i$, in stationary observation point Branch Bol'shaya Nevka 4\% of Qji, stationary observation point Branch Malaya Nevka 9\% of Qji , stationary observation point Branch Malaya Neva 19\% of Qji, where Qji is runoff volume of the Neva River measured in following year from the stationary observation point 4.

\section{Results and discussion}

Calculations of mathematical characteristics for the aforementioned stationary observation point are represented in Table 1.

Table 1. Mathematical characteristics of total phosphorus concentrations $\left(\mathrm{mg} / \mathrm{dm}^{3}\right)$ dataset in following stationary observation points on the Neva River $(\mu$ - mean value, $\sigma$ - standard deviation, $\mathrm{C}_{\mathrm{v}}$ - coefficient of variation, $\mathrm{g}-$ skewness coefficient).

\begin{tabular}{|c|c|c|c|c|}
\hline \multirow{2}{*}{$\begin{array}{c}\text { Stationary observation point, } \\
\text { catchment area }\left(\mathbf{k m}^{\mathbf{2}}\right)\end{array}$} & \multicolumn{4}{|c|}{ Mathematical characteristics } \\
\cline { 2 - 5 } & $\boldsymbol{\mu} \mathbf{( \mathbf { m g } / \mathbf { d m } ^ { \mathbf { 3 } } )}$ & $\mathbf{s}$ & $\mathbf{C}_{\mathbf{v}}$ & $\mathbf{g}$ \\
\hline Point 1, above Kirovsk city, 276000 & 0.04 & 0.02 & 0.54 & 0.58 \\
\hline Point 2, below Kirovsk city, 277000 & 0.05 & 0.02 & 0.48 & 0.10 \\
\hline Point 3, Saint-Petersburg, 278000 & 0.06 & 0.03 & 0.53 & 0.94 \\
\hline Point 4, Saint-Petersburg, 279000 & 0.13 & 0.12 & 0.97 & 2.82 \\
\hline Point 5, Saint-Petersburg, 281000* & 0.10 & 0.09 & 0.97 & 2.70 \\
\hline Point 6, Saint-Petersburg, 281000 & 0.10 & 0.08 & 0.82 & 2.46 \\
\hline Point 7, Saint-Petersburg, 281000 & 0.05 & 0.03 & 0.54 & 2.05 \\
\hline Estuary, 281600 & 0.06 & 0.6 & 0.95 & 4.80 \\
\hline
\end{tabular}

*Catchment area for points 5-7 is the same due to the lack of inflow among the city area after stationary observation point 4 .

According to the presented data, mathematical characteristics values of average annual total phosphorus concentrations vary extensively along the Neva River and appear to be quite complex and contradictory. As follows average annual total phosphorus concentrations in the Neva River increase from $1^{\text {st }}\left(0.04 \mathrm{mg} / \mathrm{dm}^{3}\right)$ to $4^{\text {th }}\left(0.13 \mathrm{mg} / \mathrm{dm}^{3}\right)$ stationary 
observation points, producing a deference of $0.09 \mathrm{mg} / \mathrm{dm}^{3}$. Subsequently from stationary observation point 4 to estuary (within the city) decreasing of concentration to $0.06 \mathrm{mg} / \mathrm{dm}^{3}$ appears.

As indicated in stationary observation point 4, average annual total phosphorus concentrations increased in comparison with upstream station 3 by an amount of 0.07 $\mathrm{mg} / \mathrm{dm}^{3}$. Consequently, if one uses average annual runoff volume in the Neva River as $2,200 \mathrm{~m}^{3}$ per second, then the average annual increment of concentrations between stations 3 and 4 (Table 1) equals $0.07 \mathrm{mg} / \mathrm{dm}^{3}$. As such, within a day the Neva River gains 13.3 tons of total phosphorus on average, on the $13^{\text {th }}$ kilometer section, yielding a total of 4,850 tons per year.

Furthermore, the drastic reduction of concentrations appears below station 4, in particular on the $8 \mathrm{~km}$ interval, where it decreases by $23 \%$, in addition on the $4 \mathrm{~km}$ interval, where there is a $38 \%$ decrease.

According to the presented data standard deviation varies from 0.02 to 0.12 , meaning a $6 \mathrm{x}$ increase. The coefficient of variation fluctuates from 0.48 to 0.97 , doubling in quantity. In the other hand, the skew coefficient rises from 0.58 to 0.97 . Incidentally, the upper values of mathematical characteristics of annual total phosphorus concentrations appear on distances varying from 48 to $12 \mathrm{~km}$ distance from the estuary. It is notable that the increase in concentrations mostly appears above the Saint-Petersburg area, and the drastic decrease occurs within the Saint-Petersburg area.

In connection with specified changes of long-term mean values of total phosphorus concentrations along the Neva River, a series of questions emerge:

- Is it possible that variations of following results are consequences of uncertainties of data?

- Is it possible that upper values of concentrations close to station 4 caused by discharge of biogenic elements into the Neva River from the territory above?

- What does determine the decreasing of average annual total phosphorus concentrations in the Neva River within the city?

- Is it possible that in different stations different methods appearing?

- Is it conceivable to use original data for analysis of phosphorus content in the Neva River?

The answers to followed issues have significant influence on further analysis of impact caused by agriculture on the Neva River runoff and its consequent evaluations over the time.

The answer to the first question is quite evident. The uncertainties in calculation of mathematical characteristics of dataset are always less than increment of average concentrations between stationary observation points.

As the answer to the second question we should mention that the manufactures which are capable of causing such a diurnal increase of total phosphorus in the Neva River do not exist.

A possible answer to the third question is the concentration of decreasing biogenic elements, which may be caused by natural factors, such as the transformation of acting elements by aquatic organisms. However, this is extremely unlikely, in this case because the time period that is required for water flow to overcomes path from station 4 to estuary is insufficient for the required transformation $[4,5]$.

Additionally, the suggestion about discharge of biogenic elements was verified. The results of verification with theory of outliers produced negative result. Furthermore, on the basis of existing methods of analysis the answers to the following aforementioned questions have not been found yet. It would appear that this requires additional research. To produce an improved analysis of variations of average annual total phosphorus concentrations in and along the Neva River we used integral curves. The results of the calculations are presented on Fig. 1.

According to Fig. 1, there are two types of integral curves. Integral curves related to the 
first type appear on the stations 4-6, to second type - on the station 1-3 and 7, 8. In the first group of curves final values are more than twice higher than analogous values of integral curves of the second type.

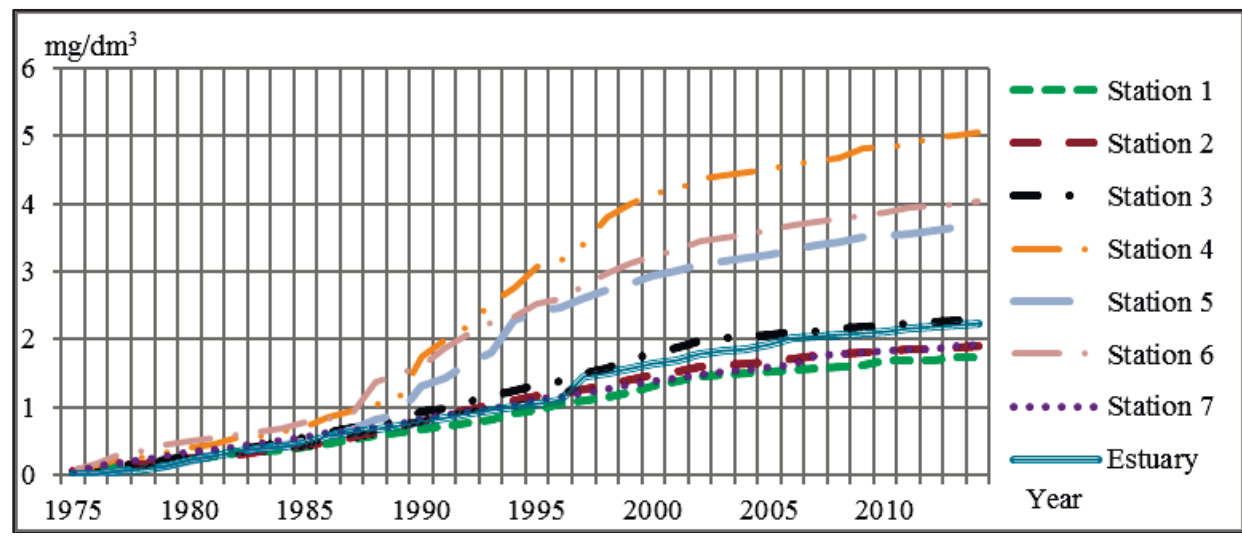

Fig. 1. Integral curves of annual average total phosphorus concentrations in the Neva River.

Due to integral curves we may specify three periods of variations for the courses of concentration integral curves. The first period appears from the starting point of observations to 1990 year, the second period from 1991 to 2002, the third period from 2003 to 2013. From 1991 integral curves of $2^{\text {nd }}$ group sharply rise up in contrast to $1^{\text {st }}$ and $3^{\text {nd }}$ groups. That indicates a significant increase of average annual concentrations in this period. Starting with 2003 the intensity of increment of average annual concentrations reads almost identically across all the stationary observation points.

The necessity in verification of homogeneity for the dataset based on mean value occurred on the basis of presence of three periods in first group of integral curves. The verification of homogeneity was implemented with Student's t-test for previously presented periods and is shown in Table 2.

According to the represented results, the series of total phosphorus average annual concentrations on the stations 4, 5, 6 cannot appear as heterogeneous according to mean value and variance. Depsite this, the whole dataset may be separated into 3 parts by the value of total phosphorus average annual concentrations. It is important to note, however, that in series 4, 5, 6 the estimates of mean values for the second part of the observation period (1991 - 2001) significantly differ from data obtained in the $1^{\text {st }}$ (from 1978 to 1991) and $3^{\text {rd }}$ (from 2002-2013) groups. The possibility that the values of average annual total phosphorus concentrations obtained during $2^{\text {nd }}$ period belong to the same statistical population as the values from $1^{\text {st }}$ and $3^{\text {rd }}$ periods, both of less than $0.1 \%$.

On the basis of presented results, a necessity of separated analysis of the data appeared. Additional analysis of the data was performed for $1^{\text {st }}$ and $3^{\text {nd }}$ periods. As a result, on Fig. 2 integral curves after excluding $2^{\text {nd }}$ period from main dataset are represented.

As represented on Fig. 2, there are two different periods: before 1990 and after 2002. Evidently, that during second period all series of observations along the Neva River show certain reduction of total phosphorous runoff. It was almost certainly caused by the efforts of the organization named «SUE «Vodokanal of St. Petersburg»»» in improvement of treatment of wastewater.The data of variation of annual concentrations of total phosphorus along the Neva River before and after removing the second period of observations is presented on Fig. 3. Fig. 3 shows that the change of annual concentrations of total phosphorus along the Neva River appears now to be more structured and corresponds to physical processes of total phosphorus runoff on urban territories. 


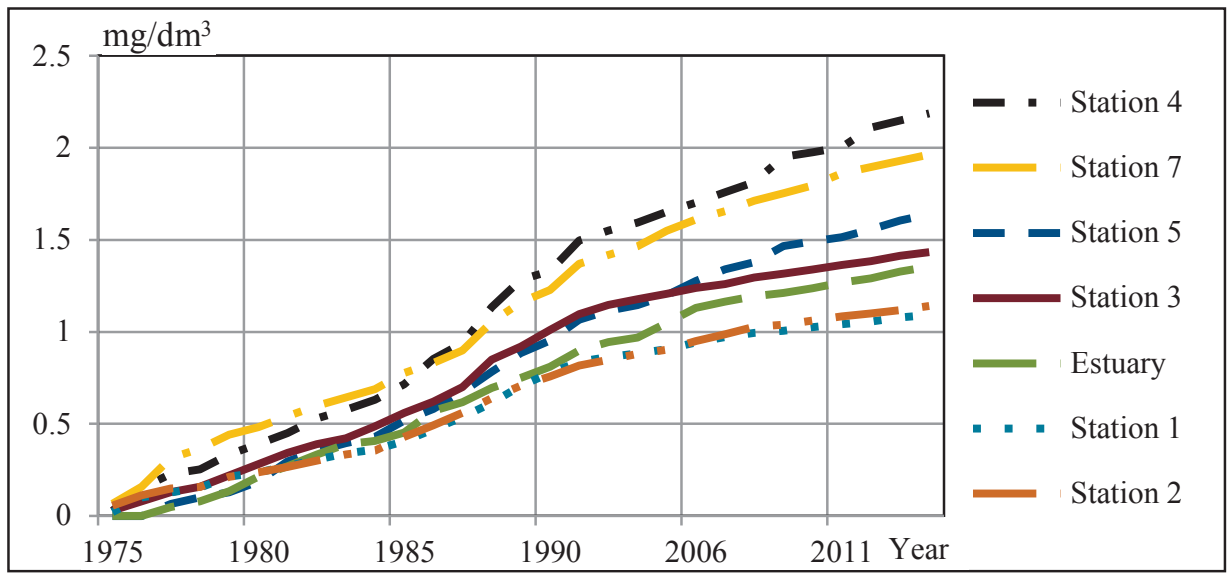

Fig. 2. Integral curves of annual average total phosphorus concentrations in the Neva River after excluding from main dataset period from 1991 to 2001.

Table 2. Evaluation of homogeneity for the dataset of average annual total phosphorus concentrations for $1^{\text {st }}$ group of stations: $\mathrm{n}_{1}, \mathrm{n}_{2}$ - the length of the period accordingly, $\mathrm{m}_{1}, \mathrm{~m}_{2}$ - average annual values for compared periods accordingly, standard deviation for compared periods accordingly, $\mathrm{t}_{\alpha}-\mathrm{t}$-test (level of significance $\alpha=5 \%$ ), t* - calculated t-test.

\begin{tabular}{|c|c|c|c|c|c|c|c|c|c|}
\hline Compared periods & $n_{1}$ & $n_{2}$ & $m_{1}$ & $m_{2}$ & $\sigma_{1}$ & $\sigma_{2}$ & $t_{\alpha}$ & $t^{*}$ & Divergence \\
\hline \multicolumn{10}{|c|}{ Stationary observation point 4} \\
\hline $\begin{array}{c}1978-1990 \text { and } \\
1991-2001\end{array}$ & 13 & 11 & 0.07 & 0.26 & 0.01 & 0.05 & 1.71 & 14.5 & $\begin{array}{c}\text { Quite } \\
\text { significant }\end{array}$ \\
\hline $\begin{array}{c}1978-1990 \text { and } \\
2002-2013\end{array}$ & 13 & 12 & 0.07 & 0.08 & 0.01 & 0.02 & 1.71 & 1.20 & $\begin{array}{c}\text { Not } \\
\text { significant }\end{array}$ \\
\hline $\begin{array}{l}\text { 1991-2001 and } \\
2002-2013\end{array}$ & 11 & 12 & 0.26 & 0.08 & 0.05 & 0.02 & 1.71 & 13.0 & $\begin{array}{c}\text { Quite } \\
\text { significant. }\end{array}$ \\
\hline \multicolumn{10}{|c|}{ Stationary observation point 5} \\
\hline $\begin{array}{c}1978-1990 \text { and } \\
1991-2001\end{array}$ & 13 & 11 & 0.06 & 0.19 & 0.01 & 0.04 & 1.71 & 11.4 & $\begin{array}{c}\text { Quite } \\
\text { significant }\end{array}$ \\
\hline $\begin{array}{c}1978-1990 \text { and } \\
2002-2013\end{array}$ & 13 & 12 & 0.06 & 0.06 & 0.01 & 0.01 & 1.71 & 0.38 & $\begin{array}{c}\text { Not } \\
\text { significant }\end{array}$ \\
\hline $\begin{array}{l}1991-2001 \text { and } \\
2002-2013\end{array}$ & 11 & 12 & 0.19 & 0.06 & 0.04 & 0.01 & 1.71 & 11.0 & $\begin{array}{c}\text { Quite } \\
\text { significant. }\end{array}$ \\
\hline \multicolumn{10}{|c|}{ Stationary observation point 6} \\
\hline $\begin{array}{c}1978-1990 \text { and } \\
1991-2001\end{array}$ & 13 & 11 & 0.07 & 0.19 & 0.01 & 0.03 & 1.71 & 13.4 & $\begin{array}{c}\text { Quite } \\
\text { significant }\end{array}$ \\
\hline $\begin{array}{l}1978-1990 \text { and } 2002- \\
2013\end{array}$ & 13 & 12 & 0.07 & 0.07 & 0.01 & 0.01 & 1.71 & 0.73 & $\begin{array}{c}\text { Not } \\
\text { significant }\end{array}$ \\
\hline $\begin{array}{l}\text { 1991-2001 and 2002- } \\
2013\end{array}$ & 11 & 12 & 0.19 & 0.07 & 0.03 & 0.01 & 1.71 & 12.9 & $\begin{array}{c}\text { Quite } \\
\text { significant }\end{array}$ \\
\hline
\end{tabular}

It is highly significant that after removing second period from calculations, a decreasing of average annual concentrations downstream in the flow of the Neva River was excluded almost completely in ranges of statistical uncertainties. Further study will thoroughly explore the reasons why the dataset appears to be not heterogeneous. Some suggestions on this topic have already been discussed in this paper. 


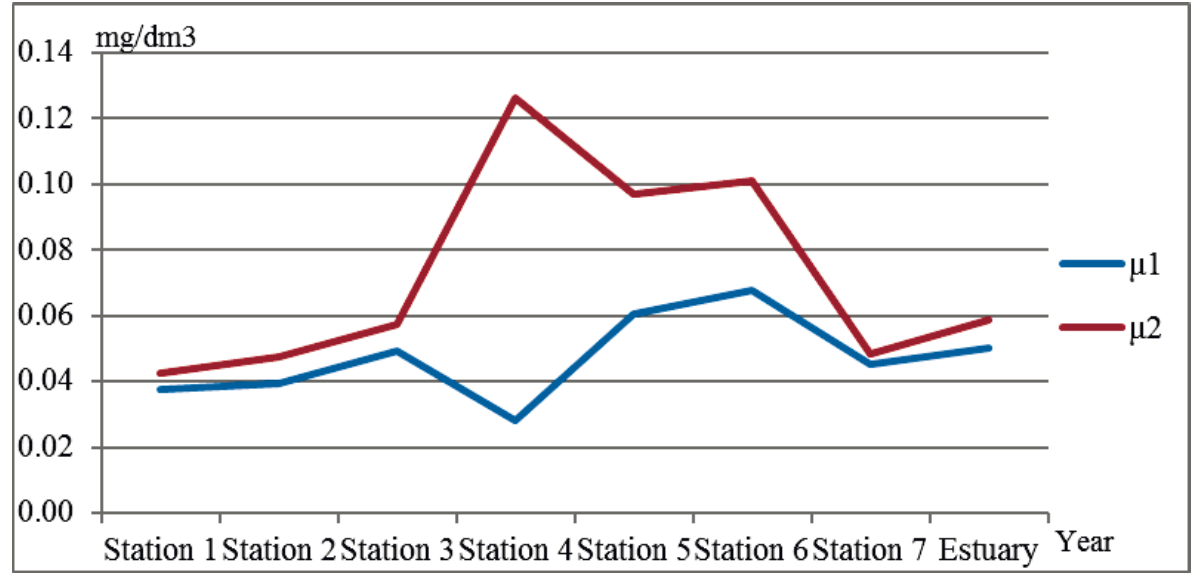

Fig. 3. Values of annual concentrations of total phosphorus: $\mu 1$ - during complete observation period (1978-2013), $\mu 2$-after removing the second period (1991-2001).

\section{Conclusions}

Original observations of the dataset of total phosphorus content along the Neva River showed the lack of linkage along the Neva River in many cases. Average annual total phosphorus concentrations observed at stationary observation points of Neva River 4, 5, and 6 significantly exceed the concentration from downstream and upstream stations. One does not yet have a sufficient physical explanation of this excess. According to integral curves of average annual total phosphorus concentrations in the series from 4-6 observation points of the Neva River, three periods 1978-1990, 1991-2001, and 2002-2013 are clearly distinguished. For the remaining series of observations, 2 periods are distinguished: 19782001 and 2002-2013. The possibility that the values of total phosphorus average annual concentrations obtained during $2^{\text {nd }}$ period $(1991-2001)$ belong to the same statistical population as the values from $1^{\text {st }}(1978-1990)$ and $3^{\text {rd }}(2002-2013)$ periods is less than $0.1 \%$. The results of separate data processing to a certain extent allowed to alleviate mentioned above controversies. The reasons of data deviation for $2^{\text {nd }}$ period (1991-2001) require further analysis.

The authors would like to thank the Northwest Department of Hydrometeorology and Environmental Monitoring for providing the dataset.

\section{References}

1. E. Smyzhova, Evaluation of with inclusion of aspects of hydrological data, 2010. [in Russian].

2. V. Shelutko Numerical analysis in hydrology (Gidrometeoizdat, Leningrad, 1991. [in Russian].

3. R. Nezhikhovskiy, The Neva river and Nevskaya guba (Gidrometeoizdat, Leningrad 1981) [in Russian].

4. D. Alexeev, V. Gal'tsova, V. Dmitriyev, Environmental monitoring: modern condition, methods and approaches (St. Petersburg, RSHU, 2011) [in Russian].

5. A. Nykanorov Hydrochemistry, (Gidrometeoizdat, St. Petersburg, 2001) [in Russian].

6. D.R. Helsel, R.M. Hirsch. Statistical methods in water resources, U.S. Geological Survey, Reston, 2002 